\title{
REFLEJOS EN EL LENGUAJE ORDINARIO DE LA UNIDAD ENTRE EL PENSAMIENTO Y EL SENTIMIENTO
}

\author{
Reflections in the ordinary language of the unity between thought and emotions
}

Gabriel Valle ${ }^{1}$

\begin{abstract}
RESUMEN
El pensamiento y el sentimiento han sido, tradicionalmente, considerados esferas independientes una de la otra. En Occidente, esta posición ha sido avalada por una milenaria tradición religiosa y filosófica. El autor del artículo sostiene que la separación entre pensamiento y sentimiento no es tan honda como suele suponerse. En particular, la experiencia del valor, que suele atribuirse al pensamiento, revela nuestra constitución afectiva. De hecho, como el autor subraya, muchas expresiones del lenguaje corriente exhiben una doble valencia: estas refieren unas veces hechos, otras veces valores. El pensamiento, pues, oscila entre juicios enunciativos y juicios valorativos.
\end{abstract}

Palabras clave: valor, pensamiento, razón, emoción, lenguaje.

\begin{abstract}
Thought and emotions have been conventionally considered to be areas apart. In the West this point of view has been endorsed by a millennial religious and philosophical tradition. The author of this paper claims that separation between thought and emotions is not as deep as is often assumed, especially as far as the experience of value is concerned, which is usually ascribed to thought, since it reveals our emotional constitution. In fact, as the author points out, many expressions of the ordinary language show a double meaning: they sometimes denote facts, sometimes denote values. Thought, therefore, fluctuates between declarative statements and evaluative judgements.
\end{abstract}

Key Words: value, thought, reason, emotion, language.

Nuestros juicios de valor están hechos de la misma sustancia de la que están hechos nuestros sentimientos. Esta frase, que recuerda vagamente una de Shakespeare, tal vez arquearía las cejas de los suspicaces, que sin dilación la rechazarían. Estos, amparados por nuestra milenaria historia cultural, demarcarían el terreno del pensamiento deslindándolo del campo de los afectos. Las valoraciones, concluirían los críticos, florecen en el primero, no en el segundo. Una cosa es la razón y otra el corazón, sentenciarían lapidarios.

\footnotetext{
1 Istituto Accademico per Interpreti e Traduttori di Trento (ISIT), docente en Filosofía y Traducción. Italia. Correo electrónico: valle.fabrizio@gmail.com
} 
¿Son infranqueables los confines entre el pensamiento y el sentimiento? ¿De alguna manera son permeables? El propósito principal de estas reflexiones es señalar las huellas, grabadas en el caudal léxico ordinario, de cierta forma de unidad entre el pensamiento y el sentimiento, una unidad más estrecha de lo que se suele suponer. Dos serán los viáticos de nuestro derrotero: primero se indicarán, en un somero bosquejo histórico, las inacabables batallas teóricas que se han entablado desde trincheras enfrentadas; acto seguido, se subrayará el papel desempeñado por nuestra índole afectiva en la facultad apreciativa.

\section{1. Érase un abismo}

Se dice a menudo que hay una frontera nítida entre la esfera del pensamiento y la del sentimiento, un verdadero abismo para algunos. Sabe Dios qué vértigo acomete a quien lo contemple. En la historia de nuestra civilización, quizás la mayor parte de los que ahí se han asomado para escrutarlo, con afán filosófico, han dejado testimonio de su hondura.

La escisión entre el pensamiento y el sentimiento es una consecuencia de la escisión entre el alma y el cuerpo (afrontada, con otro andamiaje conceptual, en el debate contemporáneo, bajo el nombre en lengua inglesa de mind-body problem). El hiato, aparentemente irreductible, entre las dos naturalezas del hombre goza de una ilustre prosapia en Occidente. Se trata de una idea sumamente antigua, tan antigua que no hay modo de datarla. Los historiadores concuerdan en que esta llegaba de Oriente a través de la doctrina de la transmigración de las almas, y que tras haber pisado suelo europeo, echaba raíces en toda el área fecundada por la civilización greco-latina. Es probable que las huellas primordiales de tal escisión hayan sido las que quedaron impresas, alrededor del siglo VI a. C, en el orfismo y en el pitagorismo.

Más adelante Sócrates, pese a que sabía que nada sabía, fijaba para siempre nuestra noción de alma: ella es la sede del pensamiento y del carácter moral del hombre. Su discípulo Platón daba un paso más allá: el alma no tiene comienzo ni fin en el tiempo. El alma inmortal contempla la verdad y la justicia, el cuerpo mortal alberga la sensibilidad y el apetito. La alegoría de los caballos del auriga ilustra de manera cristalina nuestra doble constitución. En nuestras entrañas, se pone de manifiesto la enervante tensión entre el cochero y sus corceles. Aristóteles, aun aboliendo el cielo de las ideas perennes, diferenciaba las funciones del alma. El genio de Estagira enseñaba que las virtudes éticas son disposiciones del ánimo que, cultivadas con asiduidad, desembocan en las buenas costumbres. Las virtudes dianoéticas, en cambio, son disposiciones del intelecto que, cultivadas con regularidad, desembocan en la ciencia y en la sabiduría moral. En la doctrina 
aristotélica, pues, el bien y el mal están bajo la jurisdicción de la función racional, libre de interferencias.

El cristianismo fue sin duda el vehículo más eficaz para la propagación de la teoría dualista. Así, lo que había nacido como abstrusa materia de discusión en el cenáculo de los doctos acabó siendo, bajo el influjo de la fe, en la cultura popular, el sencillo pan de cada día. La ciencia ya no hablaba griego sino latín. En la teología cristiana de los albores la noción de alma había sido reelaborada de manera que esta fuera compatible con el credo de los fieles: el alma es inmortal mas

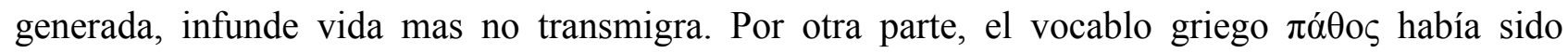
traducido por passio, que abrigaba dos acepciones sobresalientes. El latín passio era 'padecimiento' (por antonomasia, el de Cristo en la cruz); passio era también, con matiz peyorativo, 'sentimiento innoble que mueve al pecado', y en tal sentido se distinguía del clásico affectus. Se había reconstruido, pues, una pareja dialéctica que exhibía la contraposición entre acción y pasión, entre agente y paciente, entre el sujeto que ejecuta la acción y el que la experimenta. Rastros reveladores de esta oposición se hallan dispersos en las páginas de los padres de la Iglesia, desde san Agustín hasta santo Tomás.

Cabe destacar, a manera de digresión, que la voz passio, a través de sus derivados en otras lenguas, conservaba intacto el sentido de 'sentimiento pecaminoso' y adquiría gradualmente el de 'sentimiento dominante' y aun el de 'sentimiento', contrapuesto a razón (por siglos los tratadistas solían referirse a las pasiones del alma). Esta última acepción, en el uso culto, estaba condenada a languidecer. En la Inglaterra del siglo XIX, la psicología naciente, con sus ínfulas de nueva ciencia, para evitar connotaciones con aroma de filosofía vetusta o de teología, se deshacía, como de un lastre, de la palabra passion, que sustituía con emotion. Ahora volvamos a nuestro recorrido histórico.

En el Renacimiento, volvía a arder la polémica en torno al ánima, a sus intrincadas relaciones con el cuerpo. Ficino negaba que el alma estuviera hecha de la misma sustancia de que están hechos los ángeles y negaba al mismo tiempo que aquella fuera un compuesto material. El alma, decía, es un ente intermedio, el tercer grado de la existencia; es la «cópula del mundo», la bisagra en que se unen los grados más bajos de la realidad con los más altos. Pomponazzi no ocultaba sus tribulaciones: aun cuando admitía la inmortalidad del alma, en tanto dogma de fe, ponía en tela de juicio que tal cosa pudiese probarse mediante las vías de la filosofía.

Tiempo más tarde, en la Edad Moderna, Descartes avalaba la dicotomía entre alma y cuerpo. El alma, en las meditaciones cartesianas, ya no era principio de vida, sino tan solo conciencia pura. 
Menuda paradoja: un ánima exánime. Tal dicotomía era ratificada por numerosos investigadores de la naturaleza humana, entre ellos Leibniz, cuya «armonía preestablecida» atribuía a Dios la decisión, tomada antes de la era cósmica, de planificar la vida de todo hombre de modo que en él coincidieran la voluntad y la acción.

También el pensamiento alemán de la época moderna rezumaba una concepción dualista de la naturaleza humana, si bien la idea de alma, para entonces, ya había pasado por diferentes tamices y trasiegos. Muchos escritores del Romanticismo habían alzado la voz contra la razón antimetafísica de la Ilustración y habían exaltado el papel de los sentimientos en la búsqueda de los misterios de la realidad. Latía, entre poetas y novelistas, la convicción de que el arte era el campo cultivado por los sentimientos; la ciencia, el campo arado por el pensamiento. Kant, por su parte, había elevado la valla fronteriza que dividía un dominio de otro. La razón práctica, ajena a los afectos, es el árbitro inapelable del juicio moral. En el crisol de nuestras valoraciones, creía el maestro de Kaliningrado, no hay cabida para los sentimientos, salvo para uno: el respeto hacia el imperativo categórico. Rara era, en la Europa continental de aquellos siglos, la opinión discordante en este terreno. La de Spinoza era tal vez la única nota disonante en este concierto. En efecto, la sustancia única ideada por el pensador holandés había traído abajo las barreras entre naturalezas recíprocamente irreductibles. Las disonancias más clamorosas, como se verá, se oían del otro lado del canal de la Mancha.

Lo que en la historia de la filosofía ha sido por siglos una idea preponderante, se reitera, en la historia de las creencias comunes ha sido la moneda más corriente. Aún hoy, en el tercer milenio, se pueden hallar signos de un dualismo, más o menos acentuado, en la concepción del mundo actual. Aún hoy es creencia extendida que con el intelecto se piensa y se valora, mientras que con el corazón se ama o se odia. Se dice, en muchas lenguas, que "hay que actuar con la cabeza, no con el corazón”. También se dice que ciertos alegatos apelan a la emotividad, no a la racionalidad, como si una cosa y otra se excluyeran recíprocamente.

En puridad, a la hora de pensar, quizás no haya tanta distancia entre el corazón y la cabeza. Así lo atestiguan múltiples lenguas, no todas extrañas a las indoeuropeas (véase, sin rebasar los linderos occidentales, la fraseología del francés del siglo XIII, en la cual coeur 'corazón' simboliza la sede de la inteligencia). Así lo atestiguan también algunos pensadores de nuestra tradición filosófica, en franca minoría con respecto a la tendencia avasalladora, pero no por ello menos influyentes en el debate, sobre todo en el contemporáneo. 


\section{Un doble visor}

En 1745, en la Universidad de Edimburgo, David Hume inscribía su nombre en el registro de los aspirantes a la cátedra de Filosofía moral. Para demoler su candidatura, William Wishart, rector de la casa de estudios y poderoso eclesiástico, ponía en circulación las «peligrosas ideas» que Hume había expresado en el Tratado sobre la naturaleza humana. El filósofo, enterado de la campaña difamatoria que se había montado para desacreditarlo, dirigió entonces una carta a su patrocinador, John Coutts. De la carta, se habían perdido noticias hasta que, en 1967, fue publicada una copia de ella, desempolvada por dos estudiosos. ¿Qué decía la misiva? Hume explicaba ahí que nunca había negado la diferencia entre el bien y el mal, sino más bien el modo de concebirla tal como había sido planteado por un par de académicos, Clark y Wollaston. Ellos habían afirmado que las proposiciones de la moral eran «de la misma naturaleza que las verdades de la matemática y de las ciencias abstractas»y que los objetos de la moral eran de «naturaleza racional», no sentimental. Hume, en este combate de posiciones, declaraba que se alineaba con los «antiguos moralistas»y con el «señor Hutcheson».

Hume no ha sido el primero ni el último, pero ha sido tal vez el más destacado disidente de aquella tradición que abre un abismo entre el pensamiento y el sentimiento. Para el filósofo escocés, los enunciados morales traducen sentimientos morales y estos, a su vez, son inducidos por aquello que, en su idioma, se llama sympathy, un principio físico en virtud del cual, entre dos personas, lo que acontece en una induce en la otra un efecto a la distancia. Téngase presente que la lengua inglesa ha conservado este sentido de sympathy, desaparecido en otras. En la Italia del Renacimiento, por ejemplo, simpatia era, para ciertas doctrinas naturalistas, una fuerza de atracción de carácter vital que une a los seres unos con otros; para los médicos, una tendencia de determinados órganos a contraer una afección que se ha manifestado en un órgano congénere; para los músicos, una vibración de cuerdas que suenan «contagiadas» por aquellas que han sido tocadas por el tañedor.

Son los sentimientos, sostenía Hume, los que proporcionan contenido a las actitudes éticas; son los sentimientos, y solo ellos, los que impulsan a la acción. La razón, para él, no es una potencia capaz de imponerse sobre los estados afectivos, ni tiene el poder de encauzar la conducta. No, la razón, con su don alumbrador, cual antorcha entre tinieblas, no es más que un servidor de los sentimientos («slave of the passions», en palabras de Hume). Un conflicto emotivo, ante los ojos del autor, se resuelve cuando un sentimiento prevalece sobre otro. ¿Qué significa que la razón ha «dominado la cólera»? Que esta ha sido derrotada por el sentimiento de respeto hacia el prójimo, o 
por el temor a la venganza, o por el deseo de no perder los estribos, etc. ¿Qué quiere decir que los celos «han nublado el juicio»? Que aquellos, con su estremecedora violencia, se han apoderado del ánimo del sujeto al punto de impedirle ponderar una cuestión con suficiente serenidad, desapasionadamente. En un caso y en el otro, se ve que la victoria o la derrota de la razón es, en realidad, la victoria o la derrota de un sentimiento sobre otro.

Otras figuras señeras del pensamiento británico, precediendo a Hume o sucediéndolo, recorrían un camino similar al que este había hollado. Anthony Shaftesbury, Francis Hutcheson, Adam Smith y Bertrand Russell, por ejemplo, veían en los sentimientos humanos la patria de la moral. Russell, en particular, era tajante al respecto. En el curso de una célebre disputa con Frederic Copleston, transmitida por la BBC de Londres en 1948, este había preguntado a Russell cómo «justificaba» la distinción ente el bien y el mal, a lo que Russell contestó que no necesitaba justificarla, como no necesitaba justificar la distinción entre el azul y el amarillo. El contertulio objetó que lo segundo era visible, lo primero no. Russell adujo entonces que diferenciaba el bien y el mal a través de sus sentimientos.

Esta continuidad doctrinaria, que se había ido afirmando sobre todo en suelo británico, fue expandiéndose paulatinamente hacia otras latitudes, especialmente de cultura anglosajona. En 2001, por ejemplo, la filósofa estadounidense Martha Nussbaum sostenía que los sentimientos son juicios cognitivos y valorativos. El amor, el odio, la cólera, la alegría, el miedo, la tristeza, la esperanza, la añoranza, la frustración, etcétera, expresan un saber acerca de una situación y, a la vez, una evaluación, favorable o adversa. La tesis era controvertida, porque identifica el sentimiento con el juicio mismo, pero acrecentaba un caudal teórico que, en los últimos decenios, ha desaguado en la mar de la ciencia empírica.

En 1994, Antonio Damasio, un neurólogo portugués que ejerce la investigación en los Estados Unidos, había concluido, sobre la base de la praxis clínica, que determinadas lesiones en la sede cerebral de las emociones pueden perjudicar gravemente la facultad apreciativa de la víctima. Un accidente en el caso de un paciente, un tumor en el caso de otro, para poner un par de ejemplos citados por el mismo científico, habían entorpecido, en dichas personas, la capacidad de distinguir lo que para cada cual era importante. Era como si estas hubieran perdido la brújula.

La voz razón proviene del latín ratio. Razón es por tanto, por vocación etimológica, 'cuenta', 'cálculo', ‘cómputo'. Esta acepción permanece viva en el español, como demuestra, por ejemplo, la locución verbal 'dar razón de algo'. La acepción permanece viva también en el léxico filosófico histórico, señaladamente en la frase de Hobbes «ratiocinatio est computatio». La razón 
humana es la facultad que, en sus niveles más altos, se desenvuelve entre abstracciones lógicas y matemáticas. En tal sentido, ella se asemeja a un computador, capaz de establecer relaciones entre ideas.

Sin embargo, he aquí la tesis que se sustenta, el pensamiento no se agota en la razón. Antes bien, aquel la abarca y la rebasa. Consideraciones como las que acaban de ser esbozadas pretenden ensanchar los fueros del pensamiento, romper los estrechos límites del raciocinio. Pensando, conferimos valor a las cosas, sean estas decisiones, actitudes morales, promesas, objetos cotidianos, obras de arte, hallazgos científicos, programas de acción. No hay prácticamente nada en el quehacer humano que escape al horizonte del valor. El poder de estimar las cosas hunde sus raíces en nuestra trama afectiva. La facultad apreciativa posee, en la polícroma gama de los sentimientos, un carácter difuso; a menudo se oculta y se manifiesta en el tupido follaje de estos. Si los afectos no fueran el humus y el hábitat de las valoraciones, no podríamos diferenciar entre lo que apreciamos y lo que despreciamos; menos aun establecer una escala graduada que permitiera sopesar el valor de las cosas. El fiel de la balanza estaría inmóvil. Si el mundo, con sus bellezas y sus horrores, se aloja en nuestra conciencia teñido de color y de calor es porque lo escudriñamos con un doble visor.

Una vez sentada esta premisa, se tratará de exponer la doble valencia que, en el lenguaje ordinario, poseen algunas expresiones de uso frecuente.

\section{Palabras que se bifurcan}

En el lenguaje quedan fraguadas nuestras experiencias colectivas. A lo largo del tiempo, las palabras se acumulan y sedimentan en un patrimonio común. Es como si estas formaran estratos que se sobreponen unos a otros dando fe de la impredecible historia de nuestros significados. La historia de los significados, por inverosímil que parezca, forma parte integrante de la historia de la imaginación.

Muchas palabras o giros del lenguaje, nacidos con un sentido unívoco, han ido adquiriendo significados nuevos con el decurso del tiempo. Lo que aquí se quiere destacar es que algunas de esas expresiones refieren unas veces hechos, otras valores. Esta doble valencia se verifica en un sinfín de idiomas, entre ellos el español, que para nuestros fines será el centro de nuestra atención.

En los ejemplos que siguen obsérvese que, dado un término de referencia, el primer significado de este remite a un acontecimiento, el segundo a una valoración. 
La primera palabra que ha de ser aquí considerada es significado, que puede remitir a 'idea', 'concepto', o bien a 'valor', 'importancia'. Compárese la frase «el profesor ha explicado el significado de la expresión» con «el reloj que había heredado del abuelo tenía un significado para él». Algo semejante cabe decir de la voz sentido, que por una parte puede asociarse a 'idea' y, por otra, a 'finalidad valiosa'. Cotéjese la oración «no entendía el sentido de un diagrama» con «la vida tiene sentido». La palabra lógico no se sustrae a esta tendencia: en cuanto adjetivo, referido a un despliegue argumentativo, quiere decir 'consecuente'; referido a una acción, quiere decir 'cuerdo', 'sabio'. Confróntese el enunciado «su razonamiento era lógico a todas luces» con «la reforma aprobada por el gobierno no era lógica». El vocablo absurdo también se ramifica en dos direcciones, que conducen, en un caso, a 'incomprensible para el intelecto' y, en otro, a 'censurable por insensato'. Adviértase la diferencia entre la proposición «su hipótesis era absurda porque entrañaba contradicción» y «el plan que proponías era absurdo».

¿Qué puede aducirse de razón? Que el término alude, en unos contextos, a 'cosa verdadera' y, en otros, a 'buenos motivos'. En efecto, quien «tiene razón», eventualmente, dice algo cierto u orienta sus pasos bajo el impulso de un sentimiento considerado válido. Nótese a guisa de ejemplo cómo la palabra razón se desdobla semánticamente en las siguientes oraciones: «tenías razón cuando dilucidabas la causa del problema» y «tenías tus razones para deshacerte de ese sinvergüenza». La doble acepción aquí delineada es perspicua en la famosa frase de Pascal: «el corazón tiene razones que la razón no conoce».

A la vera de la verdad no puede faltar su polo opuesto: la falsedad. La voz error denota a veces esta última, a veces 'conducta imprudente o inoportuna'. Léase la frase «ha cometido un error en el examen», léase «ha cometido el error de hacer negocios audaces», y se tendrá una prueba de lo primero y de lo segundo respectivamente.

La mencionada bivalencia está también impregnada en la palaba consciente y en su contrario: inconsciente. En ambos casos, el significado oscila entre un hecho psicológico y un valor. Quien, para eximirse de una culpa, o para atenuarla, se excusa diciendo «no era consciente de la ley», declara que la ignoraba. Quien, con tono recriminatorio, le dice a alguien «eres un inconsciente», le reprocha probablemente necedad, incapacidad de discernir entre lo verdaderamente importante y lo secundario. La misma fluctuación puede detectarse en la voz acuerdo, que se desplaza entre dos extremos, el de 'concordancia sobre hechos' y el de 'estimación compartida'. En efecto, el desliz de sentido se percibe en estos dos enunciados: «hay acuerdo entre los científicos sobre el origen de las supernovas» $\mathrm{y}$ «no hay acuerdo en la familia sobre la calidad 
de la película». Algo por el estilo cabría decirse acerca del sustantivo juicio, que alterna entre 'enunciado declarativo' y 'enunciado valorativo'. El verbo juzgar es tal vez más versátil que el sustantivo con el que está emparentado, ya que equivale en ocasiones a 'analizar', en ocasiones a 'evaluar' y no raramente a 'reprobar'. Et sic de ceteris, ya que los ejemplos son incontables.

El lenguaje, decía Wittgenstein, es una ciudad antigua que ha crecido en torno a un eje: alrededor de plazas y moradas viejas, remodeladas en distintos periodos, hay un cinturón de arterias nuevas sobre las que se yerguen edificaciones posteriores. Y, se añadiría, en dicha ciudad, tejados y farolas, aceras y fuentes, exhiben con frecuencia dos lados. Son los lados entrelazados que animan a sus artífices.

\section{Referencias bibliográficas}

Battaglia, Salvatore. (1984). Grande dizionario della lingua italiana (Vol. XXI). Torino: UTET.

Castiglioni, Luigi y Mariotti, Scevola. (1996). Il Vocabolario della Lingua Latina. Torino: Loescher.

Damasio, Antonio. (1994). Descartes's Error: Emotion, Reason, and the Human Brain. New York: Putnam Publishing.

Dixon, Thomas. (2003). From Passions to Emotions. The Creation of a Secular Psychological Category. New York: Cambridge University Press.

Ernout, Alfred y Meillet, Antoine. (1951). Dictionnaire étymologique de la langue latine. Histoire des mots (Tomo II). Paris: Librairie C. Klincksieck.

Hume, David. (1967). Letter from a Gentleman to his Friend in Edinburgh (1745) (ed. por E.C. Mossner y J. V. Price). Edinburgh: Edinburgh U. P.

Hume, David. (2001). Trattato sulla natura umana. Testo inglese a fronte. Milano: Bompiani.

Le Robert. (1992). Dictionnaire historique de la langue française. París.

Nussbaum, Martha. (2001). Upheavals of Thought. The Intelligence of Emotions. New York: Cambridge University Press.

Popper, Karl y Eccles, John. (1977). The Self and its Brain. New York: Springer Verlag. 
Russell, Bertrand. (1958). Por qué no soy cristiano y otros ensayos sobre asuntos relacionados con la religión. México, D. F.: Editorial Hermes.

Sorell, Tom. (1996). The Cambridge Companion to Hobbes. Cambridge: Cambridge University Press.

Taylor, Alfred Edward. (1961). El pensamiento de Sócrates (Socrates: The Man and His Thought, 1932). México, D. F.: Fondo de Cultura Económica, colección "Breviarios".

Wittgenstein, Ludwig. (1963). Ricerche filosofiche (Philosophische Untersuchungen, 1953). Torino: Einaudi.

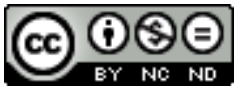

Esta obra está bajo una licencia de Creative Commons Reconocimiento-NoComercial-SinObraDerivada 4.0 Internacional 